\title{
Chemotactic responses to an attractant and a repellent by the polar and lateral flagellar systems of Vibrio alginolyticus
}

\author{
Michio Homma, Hisashi Oota, Seiji Kojima, Ikuro Kawagishi \\ and Yasuo Imaet
}

Author for correspondence: Michio Homma. Tel: +8152789 2992. Fax: +81 527893001.
e-mail: g44416a@nucc.cc.nagoya-u.ac.jp

Department of Molecular Biology, Faculty of Science, Nagoya University,

Chikusa-Ku, Nagoya

464-01, Japan

\begin{abstract}
Chemotactic responses in Vibrio alginolyticus, which has lateral and polar flagellar systems in one cell, were investigated. A lateral-flagella-defective (Pof $^{+}$Laf $^{-}$) mutant, which has only a polar flagellum, usually swam forward by the pushing action of its flagellum and occasionally changed direction by backward swimming. When the repellent phenol was added, Pof ${ }^{+}$Laf $^{-}$cells moved frequently forward and backward (tumbling state). The tumbling was derived from the frequent changing between counter-clockwise and clockwise (CW) rotation of the flagellar motor, as was confirmed by the tethered-cell method. Furthermore, we found that the tumbling cells did not adapt to the phenol stimulus. When the attractant serine was added, the phenol-treated cells ceased tumbling and swam smoothly, adapting to the attractant stimulus after several minutes. We isolated chemotaxis-defective (Che-) mutants from the Pof $^{+}$Laf $^{-}$mutant; the tumbling mutants were not isolated. One interesting mutant swam backwards continuously, with its flagellum leading the cell and its flagellar motor rotating CW continuously. A polar-flagella-defective mutant (Pof- Laf $^{+}$) stopped swimming after phenol addition and then recovered swimming ability within $10 \mathrm{~min}$, indicating that lateral flagella can adapt to the repellent stimulus. This may represent a functional difference between the two flagellar systems in Vibrio cells, and between the chemotaxis systems affecting the two types of flagella.
\end{abstract}

Keywords: Alagella, chemotaxis, che mutants, Vibrio

\section{INTRODUCTION}

Many bacteria have flagella, which are locomotive organelles. The flagellum consists of the filament, which is a helical protein tubule; the motor, which is embedded in the cell membrane; and the hook, which is a structure joining the filament and the motor (Jones \& Aizawa, 1991; Macnab, 1992). In Vibrio alginolyticus and Vibrio parabaemolyticus, which are closely related, two types of flagellar systems, polar flagella (Pof) and lateral flagella (Laf), are used for movement in the same cell, depending on environmental conditions (Blake et al., 1980). Polar flagella are generated at the cell pole and their filament is sheathed with a membrane structure which is contiguous

†Professor Yasuo Imae died suddenly of a cerebral haemorrhage on 2 July 1993. This article is dedicated to him.

Abbreviations: CCW, counter-clockwise; CW, clockwise. with the outer membrane (Allen \& Baumann, 1971). Lateral flagella are peritrichous and are not sheathed. The filament proteins, flagellins, in the two systems have different molecular masses and antigenicity (McCarter et al., 1988; Shinoda et al., 1974). Recently, it has been shown that the energy sources of polar and lateral flagellar motors are $\mathrm{Na}^{+}-$and $\mathrm{H}^{+}$-motive force, respectively (Atsumi et al., 1992; Kawagishi et al., 1995). Polar flagella, whose rotation rate is very fast (over $1000 \mathrm{~Hz}$; Magariyama et al., 1994), are produced constitutively in liquid media. Cells produce lateral flagella and elongate their bodies when they are transferred onto the surface of a solid medium. As a result, they can move and spread on such a surface (Belas \& Colwell, 1982; McCarter \& Silverman, 1990; Ulitzur, 1974, 1975). It has been proposed that polar flagella act as dynamometers to sense the outer environment and regulate lateral flagellar expression (McCarter et al., 1988; Kawagishi et al., 1996). 
Bacteria do not swim randomly but have a taxis system to move towards or away from environmental stimuli, such as chemical substances, $\mathrm{pH}$ or temperature. The four receptor proteins Tar, Tsr, Trg and Tap in Escherichia coli or Tar, Tsr, Trg and Tcp in Salmonella typhimurium are responsible for sensing the conditions (Bourret et al., 1991; Manson, 1992; Yamamoto \& Imae, 1993). The receptors are $60 \mathrm{kDa}$ integral membrane proteins with a similar structure; they span the membrane twice and consist of a periplasmic domain and a cytoplasmic domain. The periplasmic domain interacts with chemical substances and the cytoplasmic domain is responsible for signal production by interacting with cytoplasmic chemotaxis (Che) proteins and also for behavioural adaptation by methylation and demethylation of several glutamic acid residues (Stock \& Lukat, 1991). The chemotactic signal is transduced by a protein phosphotransfer cascade. Finally, the phosphorylated CheY interacts with the motor and the direction of rotation is changed from counter-clockwise (CCW) to clockwise (CW); unphosphorylated CheY cannot interact with the motor, which therefore rotates CCW (Bourret et al., 1991; Parkinson \& Kofoid, 1992).

In Vibrio species, the chemotactic mechanism has not been studied extensively, though chemotactic responses to various chemicals have been surveyed (Sojoblad \& Mitchell, 1979; Khan et al., 1993; Sar et al., 1990). In $V$. parabaemolyticus, chemotaxis-defective mutants have been isolated and the effects of chemotaxis gene (che) defects have been investigated (Sar et al., 1990). From this mutant study, it has been concluded that the rotation of polar and lateral flagella, which have distinct motors, is directed by a common chemosensory control system.

In this study, we used temporal stimulation to measure the response to chemoeffectors. We found that phenol is a repellent for $V$. alginolyticus as well as $V$. parabaemolyticus. After isolating chemotaxis-deficient mutants in $V$. alginolyticus, we classified them by behavioural responses to phenol. Furthermore, we investigated the difference between the lateral and the polar flagella chemotaxis systems.

\section{METHODS}

Bacterial strains. $V$. alginolyticus strains used were a polarflagella-defective mutant, YM19 (Pof $\mathrm{Laf}^{+}$), a lateral-flagelladefective mutant, YM4 $\left(\mathrm{Pof}^{+} \mathrm{Laf}^{-}\right)$and their parental strain 138$2\left(\mathrm{Pof}^{+} \mathrm{Laf}^{+}\right.$) (Kawagishi et al., 1995). Mutants were isolated from YM4. $V$. parabaemolyticus strains used were BB22 $\left(\right.$ Pof $^{+}$ $\mathrm{Laf}^{+}$) and RS313 (Pof ${ }^{+} \mathrm{Laf}^{-}$) (McCarter et al., 1988).

Media. PYK medium contained $0.5 \%$ polypeptone, $0.5 \%$ yeast extract, $0.4 \% \mathrm{~K}_{2} \mathrm{HPO}_{4}$ and $0.2 \%$ glucose. VC medium comprised $500 \mathrm{mM} \mathrm{NaCl}$ in PYK medium. PKG medium contained $1 \%\left(\mathrm{w} / \mathrm{v}\right.$ ) polypeptone, $0.4 \% \mathrm{~K}_{2} \mathrm{HPO}_{4}$ and $0.5 \%$ glycerol. VG medium comprised $500 \mathrm{mM} \mathrm{NaCl}$ in PKG medium.

TNM buffer contained $50 \mathrm{mM}$ Tris $/ \mathrm{HCl}(\mathrm{pH} 7.5), 300 \mathrm{mM}$ $\mathrm{NaCl}$ and $5 \mathrm{mM} \mathrm{MgCl}$. Tris motility buffer comprised $5 \mathrm{mM}$ glucose in TNM buffer.

Behavioural assay. An overnight culture in VC medium was inoculated into fresh VG medium at a 100 -fold dilution and grown at $30^{\circ} \mathrm{C}$ to exponential phase. Cells were centrifuged in an Eppendorf tube at 7000 r.p.m. for $5 \mathrm{~min}$ and the sedimented cells were suspended in Tris motility buffer. The cell suspension was diluted about 100 -fold into Tris motility buffer and chemoeffectors were added. Within $1 \mathrm{~min}$ of addition, cell motility was observed under a dark-field microscope at room temperature and recorded on videotapes. Each frame (30 frames in $1 \mathrm{~s}$ ) on the videotapes was played back on a monitor and the number of times the cell changed direction in $1 \mathrm{~s}$ was noted. At least 20 cells were measured for any given condition.

When assaying behaviour of lateral flagella, $1 \%(\mathrm{w} / \mathrm{v}$ ) polyvinylpyrrolidone K-90 (Wako Pure Chemical Industries) was added to Tris motility buffer to enhance cell motility.

Isolation of swarm-deficient mutants of the Pof ${ }^{+}$Laf $^{-}$strain. A colony of the lateral-flagella-defective $\left(\mathrm{Pof}^{+} \mathrm{Laf}^{-}\right.$) mutant YM4 was inoculated into VC medium. The overnight culture $(1 \mathrm{ml})$ was centrifuged in an Eppendorf tube at 7000 r.p.m. for $5 \mathrm{~min}$ and the sedimented cells were suspended in $1 \mathrm{ml}$ TNM buffer. The cells were sedimented again and suspended in $0.5 \mathrm{ml}$ TNM buffer. After addition of 10 or $20 \mu$ l ethyl methanesulfonate, the cells were incubated for $40 \mathrm{~min}$ at room temperature. The cells were harvested by centrifugation and resuspended in $1 \mathrm{ml}$ TNM buffer. The suspension was streaked on $0.25 \%$ agar $\mathrm{VC}$ plates and incubated at $30^{\circ} \mathrm{C}$ or room temperature overnight. This procedure to enrich non-swarming cells on $0.25 \%$ agar was repeated several times if necessary. The cells remaining at the original line were suspended in VC medium and diluted to approximately 5000 cells $\mathrm{ml}^{-1}$ with VC medium. A portion of the suspension was mixed with $0 \cdot 25 \%$ agar VC (at about $50{ }^{\circ} \mathrm{C}$ ) and plated on a $1.25 \%(\mathrm{w} / \mathrm{v})$ agar VC plate. Swarm-deficient colonies were picked up and streaked on $1.25 \%$ agar VC plates for single colony isolation. Several colonies from each mutant candidate were picked onto a $0.25 \%$ agar VC plate and their swarming abilities were tested. Flagella and motility of swarm-deficient mutants were observed by highintensity dark-field microscopy and the mutants were divided into three categories: (i) polar-flagellar-deficient $\left(\right.$ Pof $\left.^{-}\right)$; (ii) motor-function-deficient $\left(\mathrm{Mot}^{-}\right)$; and (iii) chemotaxis-deficient $\left(\mathrm{Che}^{-}\right)$.

High-intensity dark-field microscopy. Flagella were observed using a dark-field microscope (Olympus model BHT) equipped with a $100 \mathrm{~W}$ mercury lamp (Ushio USH-102). An image was recorded using a CCD camera (Sony SSC-M370) and video Hi8 (Sony S2500), and was processed by an image analysing system (AVIO Image $\Sigma$-II and EXCEL).

\section{RESULTS}

\section{Chemotactic responses of YM4 (Pof ${ }^{+}$Laf $^{-}$)}

We investigated the responses of $V$. alginolyticus YM4 to some chemicals that have been shown to be attractants and repellents in E. coli, $S$. typbimurium, V. parabaemolyticus or $V$. cholerae. To analyse the chemotactic response, we used a temporal stimulation assay in which motile behaviour is observed just after addition of a chemoeffector. We counted how many times cells changed direction in a fixed time by looking at individual frames which had been played back from recorded tapes; this was defined as the tumbling frequency. We decided to use serine and phenol as an attractant and a repellent, respectively, because they were most effective. Both chemoeffectors worked at concentrations in the millimolar range. The tumbling frequency was about $1 \mathrm{~s}^{-1}$ without chemoeffectors. When phenol was added at $5 \mathrm{mM}$, the 


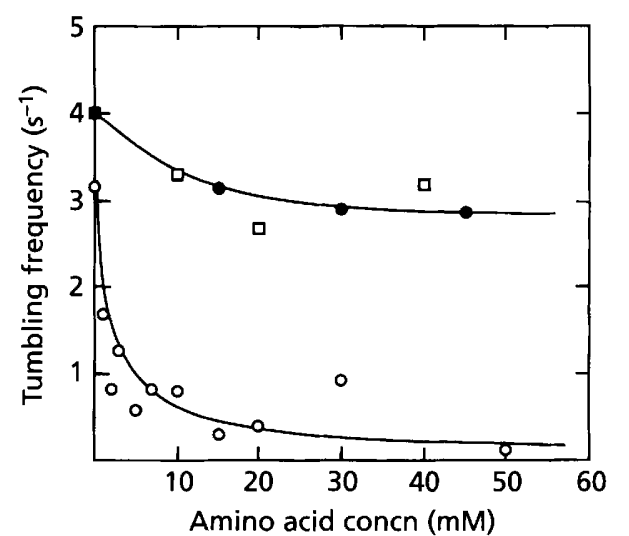

Fig. 1. Response of the polar flagellar system to an attractant After the Pof ${ }^{+}$Laf $^{-}$strain YM4 was treated with $5 \mathrm{mM}$ phenol, serine $(O)$, leucine $(0)$ or glycine $(\square)$ was added at various concentrations. Tumbling frequency was measured as the number of times a cell changed swimming direction within $1 \mathrm{~s}$.

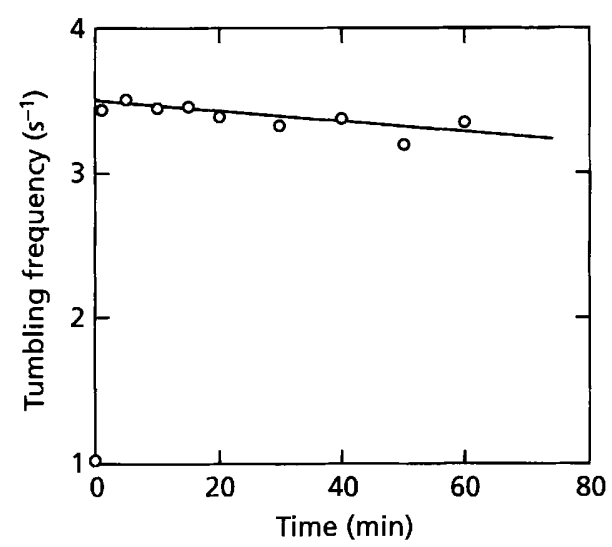

Fig. 2. Lack of adaptation of the polar flagellar system to a repellent. After the $\mathrm{Pof}^{+} \mathrm{Laf}^{-}$strain YM4 was treated with $5 \mathrm{mM}$ phenol, the tumbling frequency was measured at various intervals.

tumbling frequency was increased to $3-4 \mathrm{~s}^{-1}$. Under these conditions, frequent change between $\mathrm{CCW}$ and $\mathrm{CW}$ flagellar rotation was observed by a tethered-cell method (data not shown). After phenol addition, serine was added at various concentrations (Fig. 1). At $1 \mathrm{mM}$ serine, an attractant response was observed and the effect was saturated at 5-10 mM serine. Glycine, leucine and glycerol were not effective in generating a chemoresponse.

Next, we tried to examine the adaptation behaviour. After phenol addition, the tumbling frequency was counted at various times (Fig. 2). The tumbling frequency remained almost unchanged, even after $60 \mathrm{~min}$. The slight reduction of the tumbling frequency over the time-course may derive from the decrease in the swimming speed of the cells. After treatment with $20 \mathrm{mM}$ phenol, YM4 cells were centrifuged and the sedimented cells were suspended in fresh Tris motility buffer. By this washing procedure, the

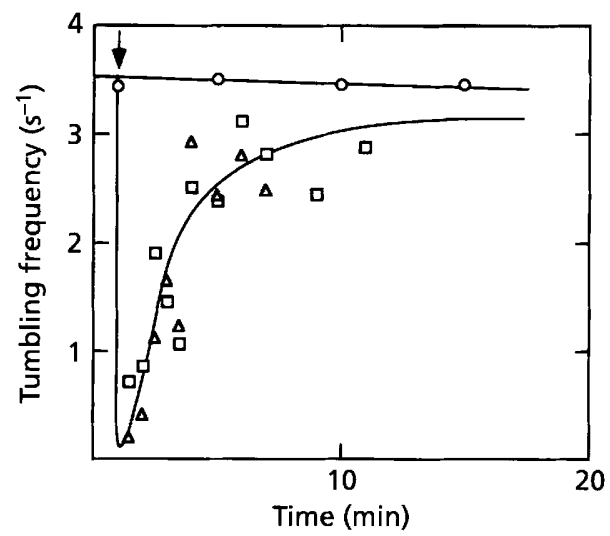

Fig. 3. Adaptation of the polar flagellar system to an attractant. After the Pof $^{+}$Laf $^{-}$strain YM4 was treated with $5 \mathrm{mM}$ phenol, serine was added at $10 \mathrm{mM}(\triangle)$ or $20 \mathrm{mM}(\square)$ at the time indicated by the arrow. $O$, No serine added. The tumbling frequency was measured at various intervals.

tumbling frequency was restored to the original level prior to the phenol addition, showing that the effect of phenol on the chemoresponse is reversible (data not shown). Upon addition of serine, the tumbling frequency of phenol-treated YM4 cells was immediately reduced to close to zero so that cells moved almost totally smoothly, then the tumbling frequency progressively increased back to the original level within about 5 min (Fig. 3).

\section{Swarm-deficient mutants}

To get chemotaxis-defective $\left(\mathrm{Che}^{-}\right)$mutants, the 40 mutants which could not swarm in $0.25 \%$ agar were isolated from YM4 ( Pof $^{+} \mathrm{Laf}^{-}$) by ethyl methanesulfonate mutagenesis. The swarm-deficient mutants were classified into three different groups: flagellation-defective ( Pof $^{-}$) mutants; motility-defective ( $\mathrm{Mot}^{-}$) mutants; and chemotaxis-defective $\left(\mathrm{Che}^{-}\right)$mutants. Among the $22 \mathrm{Pof}^{-}$ mutants, 16 showed a leaky phenotype or generated revertants whose swarm sizes were the same as the parent strain YM4. Among the five $\mathrm{Mot}^{-}$mutants, NMB85 and NMB115 had a small fraction of motile cells, NMB94 and NMB117 retained their polar flagella but were completely non-motile, and NMB104 had non-motile flagella but many cells were non-flagellate.

\section{Chemotaxis-deficient mutants}

We isolated $13 \mathrm{Che}^{-}$mutants with varying abilities to swarm in $0.25 \%$ agar (Fig. 4). Their swimming profiles were smooth-biased and directional changes occurred rarely or not at all in liquid medium. We could not obtain any tumble mutants. Only NMB86 could swarm reasonably well, although its swarm size was smaller than that of the $\mathrm{Che}^{+}$parental strain. None of the mutants except NMB75, NMB86, NMB106 and NMB111 responded to $5 \mathrm{mM}$ phenol at all and they swam smoothly after phenol addition. 


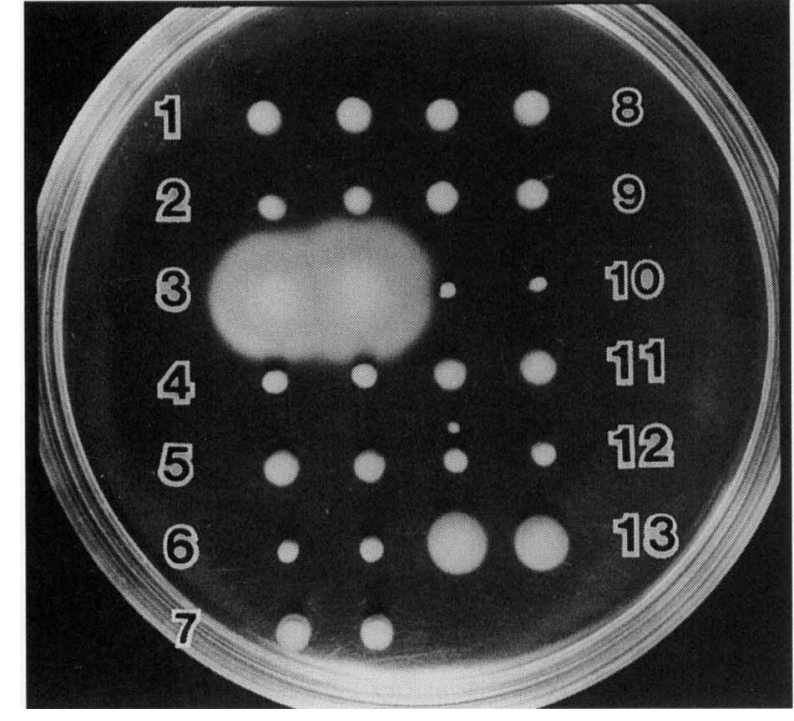

Fig. 4. Swarming profiles of mutants on $0.3 \%$ agar VC plates. Strains: 1 , NMB75; 2, NMB82; 3, NMB86; 4, NMB88; 5, NMB91; 6, NMB93; 7, NMB95; 8, NMB98; 9, NMB99; 10, NMB102; 11, NMB105; 12, NMB106; 13, NMB111. Cells were inoculated and incubated at $30^{\circ} \mathrm{C}$ for $6 \mathrm{~h}$.

When the leaky phenotype mutants NMB75, NMB86, NMB106 and NMB111 were inoculated into $0.25 \%$ agar with $5 \mathrm{mM}$ phenol, in which the swarming of the wildtype cells (YM4) was inhibited, swarming of the mutants was enhanced (Fig. 5). This may correspond to nonchemotactic swarming, which occurs more effectively at moderate tumble frequencies (Wolfe \& Berg, 1989). To analyse the response of the mutants more quantitatively, the tumbling frequency was examined at various concentrations of phenol (Fig. 6). In the wild-type cells, as well as the mutant cells, the tumbling frequency drastically increased as the phenol concentration increased from 5 to $15 \mathrm{mM}$ and at over $20 \mathrm{mM}$ phenol it was saturated at about $5 \mathrm{~s}^{-1}$ for YM4, about $3.5 \mathrm{~s}^{-1}$ for NMB86, about $2 \cdot 5 \mathrm{~s}^{-1}$ for NMB75 and about $1 \mathrm{~s}^{-1}$ for NMB106. The phenol response of the mutants seems to correspond with their swarm sizes in $0.25 \%$ agar.

NMB102 had a strange phenotype in that its swarm was very compact in $0.25 \%$ agar (Fig. 4). By light microscopy, we observed that some cells could not swim steadily, and in several cases, swimming cells were gathered together at their cell poles. When cells were examined by highintensity dark-field microscopy, it was found that they were being pulled by the polar flagella; in other words, they were swimming backwards according to the definition of Macnab \& Ornston (1977). The gathered cells were entwined by the polar flagellum of each cell (Fig. 7). The helical handedness of the polar flagellar filament of NMB102 was determined by using high-intensity darkfield microscopy and a method that involves scanning the focal plane (Shimada et al., 1975). Its handedness was the same as that of the wild-type filament, i.e. left-handed.
Thus, the NMB102 flagella seem to rotate continually $\mathrm{CW}$. We suspected that the NMB102 cells might respond to an attractant which changes the rotational direction to $\mathrm{CCW}$ bias, but they were insensitive even to $10 \mathrm{mM}$ serine.

\section{Phenol response in lateral flagella rotation}

To swim by lateral flagella, cells make a bundle out of multiple flagellar filaments, with the bundle having the same helical handedness as the individual flagella. Lateral filaments were determined to be left-handed. CCW rotation of the left-handed helix pushes the cell body and so the ceil can swim smoothly. When repellent is added, swimming is thought to be blocked by $\mathrm{CW}$ rotation of flagella, which causes bundle disassembly (Jones \& Aizawa, 1991; Schuster \& Khan, 1994).

The Pof ${ }^{-} \mathrm{Laf}^{+}$strain YM19, which possesses only lateral flagella, was grown in VC medium and the late-exponential-phase culture was diluted $100-500$-fold into Tris motility buffer containing $1 \%$ polyvinylpyrrolidone. The chemotactic response was then examined by the temporal assay method. The Pof ${ }^{-} \mathrm{Laf}^{+}$cells responded to serine and phenol which acted as an attractant and a repellent, respectively, as did the $\mathrm{Pof}^{+} \mathrm{Laf}^{-}$cells. However, Pof $\mathrm{Laf}^{+}$cells stopped by phenol gradually resumed motility, with more than $50 \%$ being motile after $7 \mathrm{~min}$ (Fig. 8). Pof ${ }^{-} \mathrm{Laf}^{+}$cells stopped by $5 \mathrm{mM}$ phenol immediately began to swim by addition of $5 \mathrm{mM}$ serine. This suggests that lateral flagella can adapt to phenol stimulation whereas polar flagella can not.

\section{DISCUSSION}

In $V$. alginolyticus, serine and phenol acted as an attractant and a repellent, respectively, and their effects were saturated at around $10 \mathrm{mM}$ as judged by a temporal assay. This concentration also corresponds to the concentration for the maximal response of $V$. parabaemolyticus in a capillary assay (Sar et al., 1990). The chemoresponse to serine and phenol in a temporal assay was similar in $V$. alginolyticus and $V$. parabaemolyticus (data not shown). These results strongly suggest that the two species have similar systems for chemotaxis as well as for flagellation. A general overview of bacterial chemoresponses has been deduced from studies in E. coli and S. typhimurium (Bourret et al., 1991). Chemoeffectors bind to the periplasmic domain of specific membrane-associated transducers (receptors) and a signal is then transmitted across the membrane to their cytoplasmic domain. The signal is processed for the excitation and adaptation pathway by the cytoplasmic components (Che proteins). The excitation signals are transmitted to the flagellar switch, which is associated with a basal body or a motor part, and is responsible for changing the direction of the flagellar rotation.

We isolated chemotaxis mutants from a $\mathrm{Pof}^{+} \mathrm{Laf}^{-}$strain of $V$. alginolyticus. These mutants were classified by their phenotypes: (i) smoothly swimming (CCW) with no 

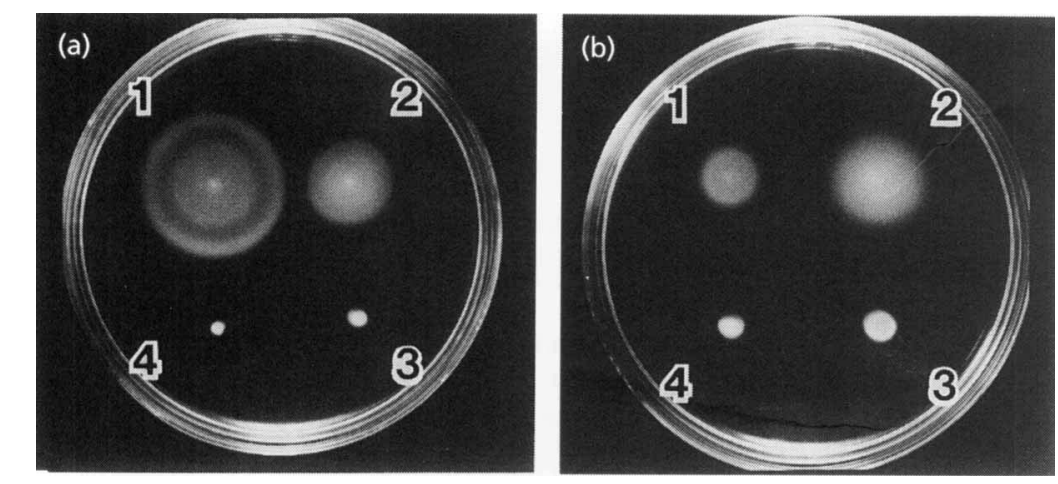

Fig. 5. Swarming profiles in the presence of a repellent. Strains: 1, YM4; 2, NMB86; 3, NMB75; 4, NMB106. Cells were inoculated on $0.3 \%$ agar VC plates without (a) or with (b) $5 \mathrm{mM}$ phenol and incubated at $30^{\circ} \mathrm{C}$ for $6 \mathrm{~h}$.

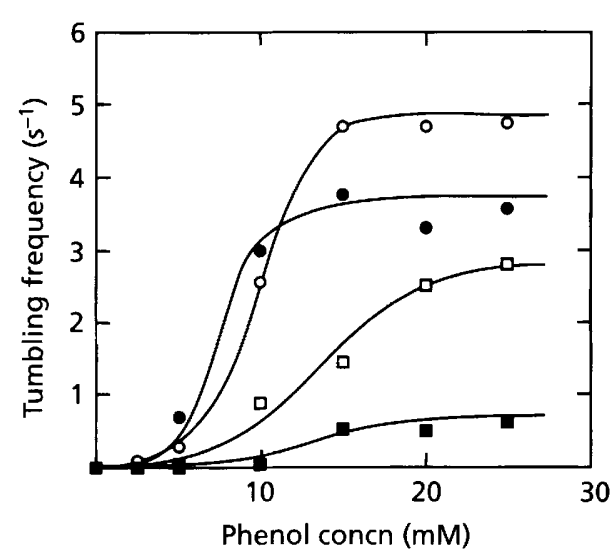

Fig. 6. Phenol-sensing ability of mutant cells. Strains: YM4 $(O)$; NMB86 (O); NMB75 ( $\square$ ); NMB106 ( $\square$ ). After addition of $1 \mathrm{mM}$ serine, phenol was further added at various concentrations and the tumbling frequency was measured.

response to phenol; (ii) smoothly swimming (CCW) with a response to phenol and serine; (iii) normal swimming behaviour but abnormal chemoresponse; (iv) backward smooth swimming $(\mathrm{CW})$ with no response to serine. Type (i) mutants were the most common (about $50 \%$ of the ones we isolated). Most of them are probably defective in genes encoding the cytoplasmic components. Type (ii) and type (iii) mutants may be leaky or may not be general che mutants. The one type (iv) mutant, the $\mathrm{CW}$-biased mutant, might have a mutation in the switch genes, the che $Y$ gene, or the gene encoding an enzyme for dephosphorylating Che $\mathrm{Y}$ as discussed in the following section.

By repellent stimulation, polar flagella frequently change the direction of rotation and do not adapt, i.e. the repellent signal remains on indefinitely. The tumbling cells were immediately restored to the smooth-swimming state after washing away phenol or adding serine. These observations show that phenol affects the chemotaxis system reversibly and we could only isolate che mutants which swam smoothly in either a forward or a backward direction. When cells were stimulated with serine after phenol addition, they swam smoothly and then reverted back to a tumbling state. This may be consistent with nonadaptation of polar flagella by phenol.
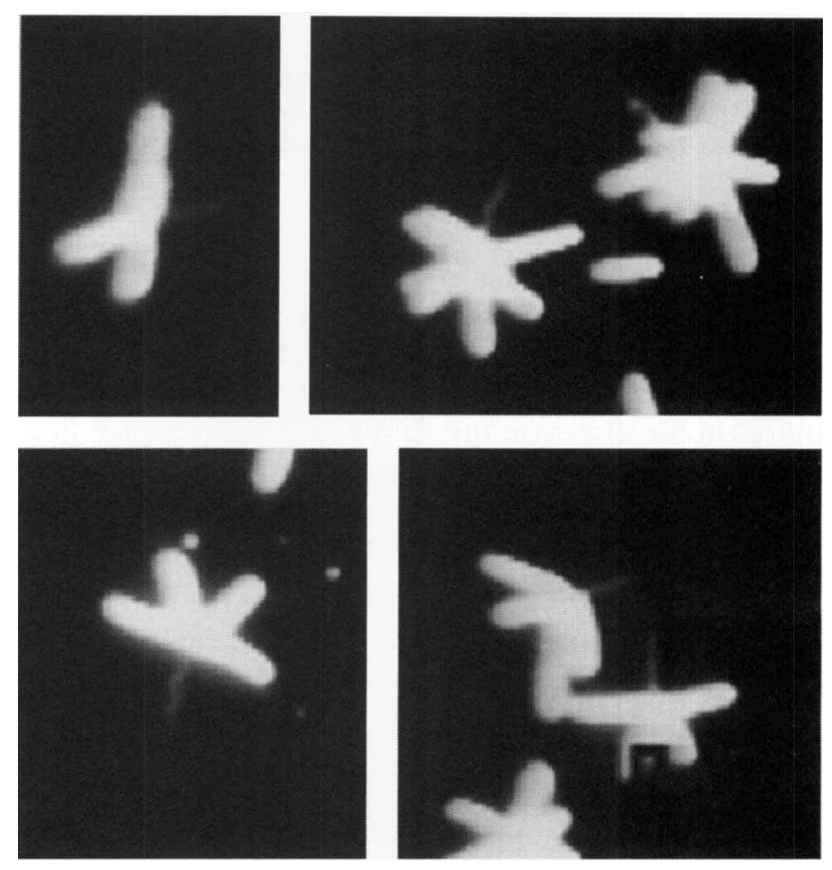

Fig. 7. Aggregation of CW mutant cells by their polar flagella. NMB102 cells were suspended in Tris motility buffer and observed by high-intensity dark-field microscopy.

In E. coli or S. typhimurium, phosphorylated CheY binds to the switch complex, causing the direction of motor rotation to be changed to CW (Barak et al., 1992; Magariyama et al., 1990; Welch et al., 1993; Yamaguchi et al., 1986). In other words, the phosphorylation and dephosphorylation of $\mathrm{CheY}$ are the signals for its association and dissociation from the switch and hence for determining the motor direction as CW or CCW. Assuming that the chemotaxis system of $V$. alginolyticus is similar, we speculate that the phosphorylated form of CheY and hence the $\mathrm{CW}$ state of the switch complex, which is led by phenol, may be very unstable and so the $\mathrm{CW}$ rotation cannot be maintained for long periods of time. Alternatively, phenol may affect $\mathrm{CheY}$ or the switch complex and destabilize the CW-biased state, though it is unlikely because phenol did not affect the smooth swimming of the che mutants (except the leaky mutants). 


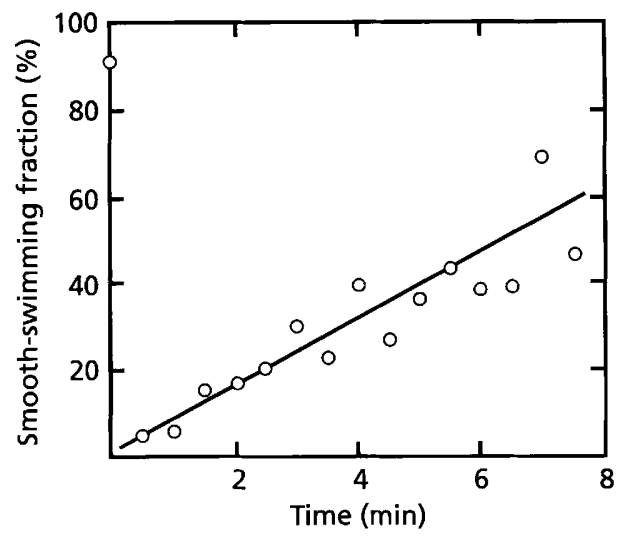

Fig. 8. Adaptation of the lateral flagellar system to a repellent. After the Pof ${ }^{-}$Laf $^{+}$strain YM19 had been treated with $5 \mathrm{mM}$ phenol in motility buffer with $1 \%$ polyvinylpyrrolidone, the smooth-swimming fraction was measured at various intervals.

On the other hand, it cannot be ruled out that phenol causes a non-specific effect on the polar motor. Even in $E$. coli or $S$. typhimurium, it is not well understood how repellents act on the chemotaxis system. It would be interesting to compare the E. coli or S. typhimurium genes with the Vibrio genes to clarify those functions. We intend to continue to clone the genes from $V$. alginolyticus (Kawagishi et al., 1994; Okunishi et al., 1996).

In $V$. parahaemolyticus, it is proposed that the two flagellar organelles (lateral and polar flagella) are controlled by a single chemosensory circuit (Sar et al., 1990). However, it has been pointed out that it is unclear if the entire chemotaxis machinery is shared (McCarter \& Silverman, 1990). We showed that the adaptation processes for lateral and polar flagella appear to be different in both $V$. alginolyticus and $V$. parabaemolyticus. Whereas both polar and lateral flagella adapt to attractant stimulation, only lateral flagella adapt to repellent stimulation. This may suggest that the chemoresponses of lateral and polar flagella to environmental stimuli are not totally identical.

\section{ACKNOWLEDGEMENTS}

We thank Dr Kenji Oosawa for invaluable discussions. We especially thank Dr Robert M. Macnab for critically reading the manuscript, and Dr Linda McCarter for kindly supplying strains. This work was supported in part by grants-in-aid for scientific researches (to I. K. and M.H.) from the Ministry of Education, Science and Culture of Japan.

\section{REFERENCES}

Allen, R. D. \& Baumann, P. (1971). Structure and arrangement of flagella in species of the genus Beneckea and Pbotobacterium fischeri. $J$ Bacteriol 107, 295-302.

Atsumi, T., McCarter, L. \& Imae, Y. (1992). Polar and lateral flagellar motors of marine $V$ ibrio are driven by different ion-motive forces. Nature 355, 182-184.

Barak, R., Welch, M., Yanovsky, A., Oosawa, K. \& Eisenbach, M. (1992). Acetyladenylate or its derivative acetylates the chemotaxis protein $\mathrm{CheY}$ in vitro and increases its activity at the flagellat switch. Biocbemistry 31, 10099-10107.

Belas, M. \& Colwell, R. R. (1982). Scanning electron microscope observation of the swarming phenomenon of Vibrio parabaemolyticus. J Bacteriol 150, 956-959.

Blake, P. A., Weaver, R. E. \& Hollism, D. G. (1980). Diseases of humans (other than cholera) caused by Vibrios. Annu Rev Microbiol 34, 341-367.

Bourret, R. B., Borkovich, K. A. \& Simon, M. I. (1991). Signal transduction pathways involving protein phosphorylation in prokaryotes. Annu Rev Biochem 60, 401-441.

Jones, C. J. \& Aizawa, S. (1991). The bacterial flagellum and flagellar motor: structure, assembly and function. Adv Microb Physiol 32, 110-172.

Kawagishi, I., Okunishi, I., Homma, H. \& Imae, Y. (1994). Removal of the periplasmic DNase before electroporation enhances efficiency of transformation in the marine bacterium Vibrio alginolyticus. Microbiology 140, 2355-2361.

Kawagishi, I., Maekawa, Y., Atsumi, T., Homma, M. \& Imae, Y. (1995). Isolation of polar and lateral flagellar defective mutants in $\checkmark$ ibrio alginolyticus and identification of their flagellar driving energy sources. J Bacteriol 177, 5158-5160.

Kawagishi, I., Imagawa, M., Imae, Y., McCarter, L. \& Homma, M. (1996). The sodium-driven polar flagellar motor of marine Vibrio as the mechanosensor that regulates lateral flagellar expression. Mol Microbiol 20, 693-699.

Khan, S., Castellano, F., Spudich, J. L., McCray, J. A., Goody, R. S., Reid, G. P. \& Trentham, D. R. (1993). Excitatory signaling in bacteria probed by caged chemoeffectors. Biopbys J 65, 2368-2382.

McCarter, L. \& Silverman, M. (1990). Surface-induced swarmer cell differentiation of Vibrio parabaemolyticus. Mol Microbiol 4, 10571062.

McCarter, L., Hilmen, M. \& Silverman, M. (1988). Flagellar dynamometer controls swarmer cell differentiation of $V$. para baemolyticus. Cell 54, 345-351.

Macnab, R. M. (1992). Genetics and biogenesis of bacterial flagella. Annu Rev Genet 26, 131-158.

Macnab, R. M. \& Ornston, M. K. (1977). Normal-to-curly flagellar transitions and their role in bacterial tumbling. Stabilization of an alternative quaternary structure by mechanical force. J Mol Biol 112, $1-30$.

Magariyama, Y., Yamaguchi, S. \& Aizawa, S. (1990). Genetic and behavioral analysis of flagellar switch mutants of Salmonella typhimurium. J Bacteriol 172, 4359-4369.

Magariyama, Y., Sugiyama, S., Muramoto, K., Maekawa, Y., Kawagishi, I., Imae, Y. \& Kudo, S. (1994). Very fast flagellar rotation. Nature 371, 752.

Manson, M. D. (1992). Bacterial motility and chemotaxis. Adv Microb Pbysiol 33, 277-345.

Okunishi, I., Kawagishi, I. \& Homma, M. (1996). Cloning and characterization of $\operatorname{mot} Y$, a gene coding for a component of the sodium-driven flagellar motor in Vibrio alginolyticus. J Bacteriol 178, 2409-2415.

Parkinson, J. S. \& Kofoid, E. C. (1992). Communication modules in bacterial signaling proteins. Annu Rev Genet 26, 71-112.

Sar, N., McCarter, L., Simon, M. \& Silverman, M. (1990). Chemotactic control of the two flagellar systems of Vibrio parabaemolyticus. J Bacteriol 172, 334-341.

Schuster, S. C. \& Khan, S. (1994). The bacterial flagellar motor. Annu Rev Biophys Biomol Struct 23, 509-539. 
Shimada, K., Kamiya, R. \& Asakura, S. (1975). Left-handed and right-handed helix conversion in Salmonella flagella. Nature 254, 332-334.

Shinoda, S., Honda, T., Takeda, Y. \& Miwatani, T. (1974). Antigenic difference between polar monotrichous and peritrichous flagella of Vibrio parabaemolyticus. J Bacteriol 120, 923-928.

Sojoblad, R. D. \& Mitchell, R. (1979). Chemotactic responses of Vibrio alginolyticus to algal extracellular products. Can J Microbiol 25, 964-967.

Stock, J. B. \& Lukat, G. S. (1991). Bacterial chemotaxis and the molecular logic of intracellular signal transduction networks. Annu Rev Biopbys Biopbys Chem 20, 109-136.

Ulitzur, S. (1974). Induction of swarming in Vibrio parabaemolyticus. Arch Microbiol 101, 357-363.

Ulitzur, S. (1975). The mechanism of swarming of Vibrio alginolyticus. Arch Microbiol 104, 67-71.
Welch, M., Oosawa, K., Aizawa, S. I. \& Eisenbach, M. (1993). Phosphorylation-dependent binding of a signal molecule to the flagellar switch of bacteria. Proc Natl Acad Sci US A 90, 8787-8791.

Wolfe, A. J. \& Berg, H. C. (1989). Migration of bacteria in semisolid agar. Proc Natl Acad Sci USA 86, 6973-6977.

Yamaguchi, S., Aizawa, S., Kihara, M., Isomura, M., Jones, C. J. \& Macnab, R. M. (1986). Genetic evidence for a switching and energy-transducing complex in the flagellar motor of Salmonella typhimurium. J Bacteriol 168, 1172-1179.

Yamamoto, K. \& Imae, Y. (1993). Cloning and characterization of the Salmonella typhimurium specific chemoreceptor Tcp for taxis to citrate and from phenol. Proc Natl Acad Sci US A 90, 217-221.

Received 27 November 1995; revised 18 April 1996; accepted 27 June 1996. 